\title{
Memory, past and self
}

\author{
Jordi Fernández
}

Received: 13 December 2004 / Accepted: 30 August 2006 / Published online: 21 October 2006

(C) Springer Science+Business Media B.V. 2006

\begin{abstract}
The purpose of this essay is to determine how we should construe the content of memories. First, I distinguish two features of memory that a construal of mnemic content should respect. These are the 'attribution of pastness' feature (a subject is inclined to believe of those events that she remembers that they happened in the past) and the 'attribution of existence' feature (a subject is inclined to believe that she existed at the time that those events that she remembers took place). Next, I distinguish two kinds of theories of memory, which I call 'perceptual' and 'self-based' theories. I argue that those theories that belong to the first kind but not the second one have trouble accommodating the attribution of existence. And theories that belong to the second kind but not the first one leave the attribution of pastness unexplained. I then discuss two different theories that are both perceptual and self-based, which I eventually reject. Finally, I propose a perceptual, self-based theory that can account for both the attribution of pastness and the attribution of past existence.
\end{abstract}

Keywords Intentionality $\cdot$ Phenomenology $\cdot$ Memory $\cdot$ Time $\cdot$ Self

\section{Introduction}

An important pre-theoretic intuition about memory is that memories are about some things. Memories have content, in the minimal sense that a subject represents the world as having been in a certain way in virtue of remembering something. The purpose of this essay is to determine how we should construe the content of memories. What kind of entities do memories put us in cognitive contact with? Are those entities mental events? Are they events in the world?

\footnotetext{
J. Fernández (ه)

Philosophy Department, Macquarie University,

W6A Building, Floor 7, Sydney,

NSW 2109, Australia

e-mail: jfernandez@scmp.mq.edu.au
} 
The question of what memories are about may be phrased in terms of truth-conditions. Our intuitive notion of memory involves the idea that, for each memory, there are conditions under which it is true and conditions under which it is false. In what follows, I shall assume that we can represent the truth-conditions of memories by means of propositions. For the sake of this discussion, propositions will be construed as ordered pairs of properties and objects. ${ }^{1}$ The issue that will concern us is, in those terms, what sort of objects and properties are the constituents of those propositions that capture the truth-conditions of memories.

For the sake of simplicity, I shall concentrate on those memories that we report as being about events in the outside world, such as the memories that we express by uttering sentences like 'I remembered that there was a book on this table an hour ago' or 'I remember that you were at the party on Friday'. And I shall use the locutions 'remembering that p', 'having a memory that p', 'perceiving that p' and 'having a perception that $\mathrm{p}$ ' in a non-factive sense. (They are not meant to entail that the relevant proposition $\mathrm{p}$ is the case.) I will proceed as follows.

In Sect. 2, I will distinguish two features of memory that our construal of mnemonic content should respect, which I shall call 'attribution of pastness' and 'attribution of existence'. In Sect. 3, I will distinguish two forms of memory and point at the specific variety that will concern us in this essay. In Sect. 4, I will distinguish two kinds of theories about memory, which I shall refer to as 'perceptual' theories and 'selfbased' theories. According to perceptual theories, the events that memory puts us in cognitive contact with are always events that some perceptual states of ours put us in contact with in the past. According to self-based theories, the events that memory puts us in cognitive contact with always involve the remembering subject. In that sense, the self is always one of the entities that memory presents to us when we remember something.

In Sect. 5, I shall argue that perceptual theories that are not self-based can potentially handle the attribution of pastness, but they have trouble accommodating the attribution of existence. In Sect. 6, I will argue that self-based theories that are not perceptual can provide a straightforward explanation of the attribution of existence, but not the attribution of pastness. At that point, I will conclude that we need to explore theories of memory that are both perceptual and self-based. Thus, in Sects. 7 and 8, I will discuss two such theories advocated by Alexius Meinong and Edmund Husserl. Finally, in sect. 9, I will propose an alternative perceptual, self-based theory that sits easily with both the attribution of pastness and the attribution of existence.

\section{Explanandum and methodology}

The two features of memory that we will be focusing on appear in Thomas Reid's discussion of memory in the third of his Essays on the Intellectual Powers of Man. Among those principles about memory that, according to Reid, 'appear obvious and certain to every man who will take the pains to reflect upon the operations of his own mind', he mentions these two:

\footnotetext{
1 Thus, I will take the proposition that represents the truth-conditions of a certain memory $\mathrm{M}$ to be an ordered pair of an object $\mathrm{o}$ and a property $\mathrm{P}$, where o having $\mathrm{P}$ is what it takes for $\mathrm{M}$ to be true. We can refer to pairs of that sort with expressions of the form ' $<\mathrm{P}, \mathrm{o}>$ '. (As far as I can see, nothing in the discussion to follow hangs on a 'Russellian' view about the nature of propositions.)
} 
Memory implies a conception and belief of past duration; for it is impossible that a man should remember a thing distinctly without believing some interval of duration, more or less, to have passed between the time it happened and the present moment [...].

The remembrance of a past event is necessarily accompanied with the conviction of our own existence at the time the event happened. I cannot remember a thing that happened a year ago without a conviction as strong as memory can give, that I, the same identical person who now remember that event, did then exist (Reid, 1994, p. 208).

These two features of memory highlighted by Reid will suffice as a first approximation to our explanandum: If a subject remembers something, then she will believe of the remembered event that it happened in the past. Similarly, if a subject remembers something, then she will believe that she existed at the time that the remembered event happened.

This is just a first approximation because both of Reid's claims are quite problematic if we read them literally. Suppose that a given subject has a certain memory, but she also has what she takes to be overwhelmingly strong evidence that her experience is not a memory. Then, she may form neither the belief that the event that she seems to be remembering happened in the past nor the belief that she existed at the time that it supposedly happened. Nonetheless, Reid's two claims do point at some interesting facts about memory. The basic observation is that, in normal circumstances, if we remember something, then we are inclined to believe that the remembered events happened in the past and that we were alive at the time that they happened. Basically, in the absence of conflicting collateral information (and provided that other standard conditions regarding our conceptual repertoire and focus of attention hold), memories predispose us to having those beliefs. This is the observation that will constitute the starting point of our discussion.

We can capture the two features of memory that we need to account for in the following 'attribution of pastness' (for short, 'AP') and 'attribution of existence' (for short, 'AE') principles:

\section{AP for every subject $\mathrm{s}$ and proposition $\mathrm{p}$ :}

Normally, if $\mathrm{S}$ remembers that $\mathrm{p}, \mathrm{S}$ is thereby inclined to believe that, in the past, it happened that $\mathrm{p}$.

AE For every subject $S$ and proposition $p$ :

Normally, if $\mathrm{S}$ remembers that $\mathrm{p}, \mathrm{S}$ is thereby inclined to believe that she existed at the time that $\mathrm{p}$.

These two principles suggested by Reid's observation should play a constraining role in our theorizing about the intentionality of memory. Any hypothesis about the kind of entities that memories put us in cognitive contact with should respect AP and AE. By 'respect', I mean that either the hypothesis in question should explain why they hold true or it should at least give us some reason to expect a future explanation that is compatible with it. ${ }^{2}$ My project in this essay is to put forward a hypothesis about the content of memories that meets those constraints.

2 The second disjunct is worth emphasizing, since we should not rule out the possibility that, ultimately, an explanation of either AP or AE is an explanation 'at the sub-personal level'. That is, an explanation in terms of the underlying mechanisms whereby memory conveys information to our 


\section{Episodic memory and semantic memory}

We may distinguish two varieties of memory for perceivable events. In this discussion, we shall only be concerned with one of them.

Suppose that, when I was a child, my parents took me to the zoo and I saw that there was an albino gorilla there. There are two different senses in which I can now be said to remember that an albino gorilla lives at the local zoo. The first sense involves the fact that I am in an intentional state wherein it seems to me that a certain event was the case. This, in turn, is due to the fact that the content of that state relates, in some systematic way, to the content of an earlier intentional state of mine, namely, a perceptual state of the event in question. Presumably, the intentional state in which I am when I remember something in this sense involves some imagery of the event and it elicits some awareness of it in me. In this sense, I may be said to remember that an albino gorilla lives at the zoo only if I can produce some details about what the gorilla looked like, what he was doing on the relevant occasion, and so on.

But notice that there is a different sense in which I may be said to remember that an albino gorilla lives at the zoo. This is the sense in which I acquired the belief that the albino gorilla lives there some time in the past, I now believe that the gorilla lives there, and there is some relation between the two beliefs in virtue of which the fact that I have the latter belief can be explained in terms of my having had the former. In this sense, I may be said to remember that an albino gorilla lives at the zoo even if I cannot produce any detail about what the gorilla looked like or what he was doing on the relevant occasion.

I shall refer to the first sort of cognitive achievement as 'episodically remembering' and to the second sort as 'semantically remembering' ${ }^{3}$ Accordingly, for any subject who remembers a given event episodically, I will call the intentional state in which that subject is an 'episodic memory' of the event and, for any subject who remembers a given event semantically, I shall refer to the subject's belief that the event was the case as a 'semantic memory' of it. The focus of this essay is episodic memory. The question that I am concerned with is what episodic memories are about or, in other words, what kinds of objects and properties are involved in the truth-conditions of episodic memories.

\section{Two approaches to memory}

We may also distinguish two different theoretical approaches to memory. First, there is a general framework wherein memories are constrained by past perceptions of the subject. The tenet that characterizes this approach to memory is that the content of a memory depends on the content of the past perceptual experience wherein that memory originates. Essentially, this dependence comes down to the idea that, in memory, there can be nothing that was not perceived in the past. Thus, the basic idea that guides

\footnotetext{
Footnote 2 continued

brains about our environment. For all we know, it is possible that the only explanation of why our two platitudes hold true is an explanation of this kind. Thus, we should not expect from a hypothesis about what memories are about that it explains AP and AE. But it is still reasonable to expect from it that it can accommodate such an explanation.

3 I am borrowing this terminology from Tulving's, (1972). The first version of this distinction that I am aware of is in Russell's, (1921).
}

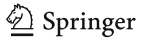


this approach to memory can be captured in a certain requirement that something must meet in order to qualify as part of the content of a memory. The requirement is basically that it must have been part of the content of the past perceptual experience wherein the memory originates. More precisely, the thought is that if a given subject $\mathrm{S}$ has a certain memory $\mathrm{M}$ and $\mathrm{M}$ is about a given event $\mathrm{E}$, then the following two conditions must obtain:

a) Previous perception condition

$\mathrm{S}$ has previously perceived that $\mathrm{E}$.

b) Dependency condition

The fact that $\mathrm{S}$ perceived that $\mathrm{E}$ is responsible for her having $\mathrm{M}$ now.

We can call those theories that subscribe these conditions on mnemonic content 'perceptual theories' of memory. (Likewise, I shall call the collection of perceptual theories the 'perceptual framework' of memory. $)^{4}$

There are several possible perceptual theories that can endorse the two conditions above. The reason for this flexibility is that those conditions are just meant to be necessary conditions for something to count as the object of a given memory. The characterization of the perceptual framework that I have just put forward is neutral on whether a perceptual theorist will also take them be sufficient or not. Thus, we can imagine at least two types of perceptual theories. Some perceptual theories will hold the two conditions above to be necessary, but not sufficient, in order for something to be part of the content of a given memory. Other perceptual theories will hold them to be both necessary and sufficient. We can call them 'weak' and 'strong' perceptual theories, respectively. Advocates of both types of theories would agree that the content of a given memory depends on the content of a past perceptual experience. The difference is basically the following. Advocates of the weak type of perceptual theory would claim that, in the content of a given memory, there can be nothing more than what there was in the content of an appropriately connected perceptual experience, but there may be less. By contrast, advocates of the strong type of perceptual theory would claim that the content of a memory experience is identical to the content of an appropriately connected perceptual experience. For the purposes of this discussion, I will be concentrating on weak perceptual theories. Thus, in what follows, talk of perceptual theories should be understood as talk of weak perceptual theories unless otherwise specified. ${ }^{5}$

In addition, there is a kind of theoretical approach to memory that focuses on the presence of the self in memory. Theories of this kind require that the information carried by any given memory is information about the remembering subject. According to these theories, then, the facts that we remember are always facts about ourselves or, to put it in other words, the self is always one of the intentional objects of memories.

\footnotetext{
4 The British empiricists are often read as perceptual theorists of memory. This seems accurate of David Hume. Hume is, in the terminology that I am about to introduce, an early 'strength' theorist. See, for instance, (Hume, 1978, p. 85).

5 I will concentrate on weak perceptual theories because strong perceptual theories are rather implausible. I thank an anonymous referee for pointing out the reason to me: It is plausible to think that details in the content of an intentional state such as a memory can be lost as time goes by. It seems too strict to demand that, unless the content of this experience that I am now having is just as rich as the content of a past perceptual experience that it originates in, this experience that I am now having cannot be a memory. This seems too strong a requirement, and it is exactly what strong perceptual theories require.
} 
Let us call these theories 'self-based' theories of memory. (Accordingly, we can call the collection of self-based theories the 'self-based framework' of memory.)

The characterizations of the self-based and perceptual frameworks that I have just offered are considerably broad. Thus, the characterization of perceptual theories is neutral on whether, according to them, those memories that we report as being about perceived events put us in cognitive contact with events 'out there', in the world or, by contrast, they put us in cognitive contact with mental properties and mental particulars of some kind. That will depend on the theorist's specific position about the intentionality of perception. Similarly, the characterization of self-based theories is quite vague, since there are various ways in which information about a subject can be 'carried by' her own memories. As a result, very different theories may count as self-based theories.

This is deliberate, since the categories of perceptual theory and self-based theory presented above are not meant to be exclusive. They are meant to be overlapping. They are characterized so as to leave logical room for theories that are both perceptual and self-based. For the next two sections, though, I wish to evaluate the prospects of theories that are perceptual but not self-based and theories that are self-based but not perceptual. I will refer to the former as 'strict perceptual theories' and I will refer to the latter as 'strict self-based theories'. (Accordingly, the expressions 'strict perceptual framework' and 'strict self-based framework' will refer to the respective collections of theories.) I shall argue that strict perceptual theories have trouble accounting for AE whereas strict self-based theories have trouble accounting for AP.

\section{Memory and perception}

As mentioned above, perceptual theories of memory can incorporate different views about perception. However, if we concentrate on strict perceptual theories for the moment, then a certain view about perception naturally comes to mind. This is the view that, in perception, we are only aware of the existence and nature of objects that exist in the surrounding physical world, independently of us. Clearly, if we add this view about perception to the two conditions that, according to perceptual theories of memory, something must meet in order to be part of the content of a memory, then the kind of theory of memory that we obtain is a strict perceptual theory. It holds that the events that we remember are always events that we perceived in the past. And it holds that those events are constituted by some objects that exist independently of us, in our physical surroundings, and some of the properties that they have. An evaluation of strict perceptual theories of this kind can help us decide whether strict perceptual theories of memory square with AP and AE or not.

Explaining the attribution of pastness within the strict perceptual framework is a challenging task. Consider my memory of an albino gorilla living at the zoo. If the content of that memory must have been part of the content of my past perception of the gorilla, then why do I think that the gorilla was living at the zoo when I remember him but I think that he is living at the zoo when I perceive him? What accounts for the fact that my memory has the power to immediately elicit in me a belief about the past but my perception does not? As far as I can see, the only answer that is available to strict perceptual theorists is that the relevant difference between memories and corresponding perceptions does not lie in what is being presented to the subject in each case, but in how it is being presented. Naturally, the challenge for the strict 
perceptual theorist is to produce a notion of 'how events are presented' that can do the work of explaining why a subject thinks that an event happened in the past when she remembers it (as opposed to when she perceives it). There are at least three broadly perceptual strategies that seem to have reasonable prospects of accomplishing this.

The first strategy appeals to the notion of vivacity. Arguably, the same event can be presented to a subject in two different instances with different degrees of vivacity. Thus, the strict perceptual theorist could claim that memories do not present to their subjects any more events than those already presented to them by their past perceptions. Still, memories present them not as vividly as perceptions. In fact, there is a line of research within the psychology of memory that pursues this idea in order to explain why we place remembered events in the past. These are the so-called 'strength theories' of memory. ${ }^{6}$ According to strength theorists, what explains the fact that a subject thinks that a given event happened in the past when she remembers it is the degree of vivacity that her memory enjoys. ${ }^{7}$

The second strategy appeals to the notion of difficulty of access. Arguably, the very same event can be presented to a subject when she is in either one of two different states, even though the amount of effort that she needs to make in order to occupy each of those states is different. As a matter of fact, according to some psychological theories, which we may refer to as 'attributional theories' of memory, the reason why a subject judges a given experience that she is having to be a memory has a lot to do with that kind of effort. Attributional theories claim that the reason why a subject takes a certain experience that she is having to be a memory is a characteristic feeling of familiarity that accompanies the remembered event. And, importantly, it is claimed that such a feeling of familiarity is due to the ease with which the event comes to mind, or the relative fluency of accomplishing a task that requires identifying the event in question. ${ }^{8}$ Now, these psychological theories are not really concerned with AP. They are concerned with our basis for attributing a certain source to the information that we are presented with when we have a memory. (In philosophical jargon, the issue they are concerned with is an issue of self-knowledge.) But the strict perceptual theorist could use some of their resources to try to explain AP. The strict perceptual theorist could claim that an event that is presented to a subject in a memory must have been presented to her in an appropriately connected past perception, but the two states differ in that the subject typically needs to make an effort to occupy the former but not to occupy the latter. And this is why perceptions elicit beliefs about the present whereas memories elicit beliefs about the past.

The third strategy appeals to the notion of context of presentation. One and the same event may be presented to a subject in a given perception and a later memory 'in different ways' in the following sense: The context in which the subject was when she perceived the event could be different from the context in which the subject is

\footnotetext{
${ }^{6}$ For strength explanations of our tendency to locate remembered events in the past, see Anisfeld and Knapp (1968), Brown, Rips, and Shevell (1985), Hinrichs, (1970), and Morton, (1968).

7 Strictly speaking, according to some theorists, what explains the fact that we locate remembered events in the past is the 'amount of perceptual detail' involved in the relevant memory, where the amount of perceptual detail of a memory is the number of propositions that a subject can produce about the remembered event. See Brown et al. (1985) for details.

8 More specifically, it is argued that the reason why, in a recognition test, a subject judges that she is remembering certain items and not others is the ease with which certain items 'jump out' during the test. And the reason why, in a free recall test, the subject judges that she is remembering certain items is the ease with which those items 'pop into mind'. See Baddeley, (1982) and Jacoby and Dallas (1981) for details.
} 
when she remembers it. (Thus, you may have perceived a snow-covered field on a cold winter night but remember it while being at the beach on a hot summer afternoon.) Now, a certain view in the psychological literature tries to use the notion of context overlap, or matching, to explain the likelihood that a particular item will be recalled in a free recall task. ${ }^{9}$ The basic idea within this 'context overlap' theory is that the amount of contextual overlap between the time of recall and the time of presentation is proportional to the likelihood that a particular item will be recalled. This view is not concerned with AP either. (It is concerned with the factors that constrain the reliability of memory.) But, once again, there is no reason why the strict perceptual theorist could not pursue a similar idea to explain AP. It is open to the strict perceptual theorist to suggest that the reason why a subject thinks that a given event happened in the past when she remembers it is the fact that there is not much overlap between the context in which the event was perceived and the context in which it is now remembered.

Now, it difficult to imagine that either of the three factors above will help us account for AP on its own. However, it seems plausible that a combination of factors that include the three factors above could help us explain why we place remembered events in the past. The precise contribution that each factor may make is obviously an empirical matter. Nevertheless, it does not seem unreasonable to expect that some combination of the three strategies above may eventually allow us to accommodate an explanation of the attribution of pastness within the strict perceptual framework.

What about AE? According to perceptual theories of memory, for a given memory to be the memory of a specific event, the subject must have perceived the event, and her past perception must be appropriately connected to her current memory. Thus, the content of the memory state that I would express by uttering 'I remember an albino gorilla living at the zoo' is meant to be part of the content of a past perception that is appropriately connected to that state. That perception is the state that, in the past, I would have expressed by uttering 'I perceive an albino gorilla living at the zoo.' And, according to the kind of strict perceptual theories that we are considering, its content involves the gorilla, and the properties of being white and living at the zoo.

Now, if the content of my memory is determined by the event that is constituted by the gorilla having the properties of being white and living at the zoo (if, assuming that no content has been lost, those are the entities that my memory is presenting to me), it is hard to see why I am inclined to think that I existed at the time that event was the case. What reason do I have to think that? After all, according to strict perceptual theories, the event that my memory presents to me is not supposed to involve me, but an albino gorilla. So why would my having information about an albino gorilla lead me to believe something about myself, namely, that I existed at a certain time in the past? The AE feature of memory becomes a mystery within the strict perceptual framework.

\section{The self in memory}

Let us now consider strict self-based theories of memory. My aim in this section is to show that such theories can explain the attribution of existence but not the attribution

9 See Glenberg, Bradley, Kraus, and Renzaglia (1983), and Glenberg et al. (1980). On the relevance of context for memory, see Godden and Baddeley (1975) as well.

型 Springer 
of pastness. To illustrate this, I shall focus on what I take to be one of the most natural strict self-based theories of memory, namely, what we may call the 'reflective view' of memory.

I call the reflective view of memory the position according to which the content of a given episodic memory is that its subject was in a certain mental state in the past. Michael Martin sometimes seems to endorse a version of this theory. Thus, Martin writes:

When one recalls an episode, on the current account, one recalls the original episode of apprehension. That episode has as its object events which one perceived, or of which one was an agent. [...] In recalling such an episode, the objects of that episode are recalled as the objects apprehended at that earlier time. Although an episode of recall has as its object the initial experience which was the apprehending of the event, it has thereby as a proper part of its content what was then apprehended (Martin, 2001, p. 278).

The basic idea seems to come down to the following view. For every subject $\mathrm{S}$, memory experience $\mathrm{M}$ and proposition $\mathrm{p}$ :

\section{Reflective view}

If $S$ has a memory experience $M$ that she would express by saying that she remembers that $\mathrm{p}$, then the content of $\mathrm{M}$ is the proposition: $<$ Having had a perceptual experience of $\mathrm{p}, \mathrm{S}>$

The reflective view is a strict self-based theory. It is self-based because, according to it, what I am in cognitive contact with when I claim to remember that a certain event happened is, strictly speaking, my having perceived it. Furthermore, I take it to be a strict self-based theory because, as far as I can see, such a view is not meant to be a perceptual view. Otherwise, the previous perception condition would force the reflective theorist to claim that the objects of our perceptual experiences are those experiences themselves, which is highly implausible.

The reflective view can easily explain why $\mathrm{AE}$ is true. If the view is correct, then one cannot remember a perceivable event but by being aware of having perceived it. This means that any cognitive contact with a past perceivable event that memory may provide one with is mediated by an awareness of one's own perceptual experiences and, therefore, by some kind of awareness of oneself. It is not surprising, then, that one tends to believe that one existed at the time that those perceivable events that one remembers happened. After all, one is always presented to oneself as perceiving those events in one's memories of them.

The hard feature of memory to explain for the reflective view is AP. Building the subject into the content of memories may help us to explain why we think that we existed when those perceivable events that we remember happened but it does not help us to explain why we think that those events happened in the past. One way of looking at this difficulty is the following. Consider a given memory of mine (call it M) that I report as being about a certain perceivable event E. The basic tenet of the reflective theory is that, strictly speaking, the content of $\mathrm{M}$ is not constituted by $\mathrm{E}$ being the case but by my having a certain perceptual experience of $\mathrm{E}$ being the case. Suppose that this is correct. What makes M intentionally different from an introspective state whereby I am aware of my perceptual experience of $\mathrm{E}$ being the 
case? Even if we grant that the proper objects of memories are the subject's perceptual experiences, we still want to allow for a contrast between introspection and memory, both of which put us in direct cognitive contact with our own perceptual experiences if the reflective view is correct. Presumably, the contrast amounts to the fact that the former presents our current perceptual experiences to us as being present whereas the latter gives us cognitive access to our past perceptual experiences as being past. The challenge for the reflective view is to make sense of this contrast. Explaining why it seems to us that remembered mental experiences happened in the past does not seem easier than explaining why it seems to us that remembered events 'out there', in the world, happened in the past. So the move that allows reflective theorists to account for $\mathrm{AE}$ does not constitute much progress as far as explaining AP is concerned.

The difficulties that the reflective view faces regarding AP suggest that strict selfbased theories will have trouble accounting for the attribution of pastness even though they can easily accommodate the attribution of existence. By contrast, we have seen that strict perceptual theories seem to have reasonable prospects of explaining the attribution of pastness but they do not seem to be capable of accounting for the attribution of existence.

\section{Intersecting approaches: Meinong}

The lesson I draw from the discussion so far is that we need a theory of memory that incorporates those features of perceptual theories that allow them to account for AP as well as those features of self-based theories that allow them to account for AE. The purpose of the next two sections is to show that it is not easy to design such a theory. To illustrate this, I shall discuss two perceptual, self-based theories of memory that we can find in the phenomenological tradition.

Consider, first of all, Alexius Meinong's views on memory. While discussing the epistemological significance of memory, Meinong writes the following:

Almost everybody would be willing to admit that I cannot remember something that I have not experienced; similarly, most people would also agree that I really cannot experience what takes place outside of me, but only what goes on within me (Meinong, 1973, p. 256).

Meinong endorses the previous perception condition for memories ('I cannot remember something that I have not experienced'). In addition, he seems to endorse a sense-data view about the content of perceptions (since, according to Meinong, I can only experience 'what goes on within me'). This leads Meinong to a sense-data theory of memory:

Thus we have admitted that we can actually and directly remember only the data of the mental life [...] (Meinong, 1973, p. 256).

The contents of memories are inherited from the contents of past perceptions that the subject had. But those contents are identical to certain 'mental data'. As a result, Meinong claims, we can only remember those mental data. So Meinong's theory seems to amount to the following view. For every subject $\mathrm{S}$, memory experience $\mathrm{M}$ and proposition $\mathrm{p}$ : 
Meinong's view

If $\mathrm{S}$ has a memory experience $\mathrm{M}$ that she would express by saying that she remembers that $\mathrm{p}$, then there is a collection of sense data $\mathrm{D}$ and a perceptual experience $\mathrm{E}$ such that:

(1) S had $\mathrm{E}$ in the past and she would express $\mathrm{E}$ by saying that she perceives that $\mathrm{p}$.

(2) The content of $\mathrm{E}$ is $<$ Occurring in me, $\mathrm{D}>$.

(3) The content of $\mathrm{M}$ is $<$ Occurring in me, $\mathrm{D}>$.

This view is a perceptual theory of memory because the collection of past sense data $\mathrm{D}$ is meant to be the object of a past perception of the subject. But it is also a self-based theory. For Meinong's idea is that the mental data in question are presented to the subject as her own, that is, as the data of the subject's own mental life. Thus, there is a clear sense in which information about the subject is contained into the content of her memory experiences.

Unfortunately, whether or not this theory has the resources to deal with AE and $\mathrm{AP}$, it is quite implausible for independent reasons. The view that Meinong subscribes about perception is susceptible to well-known objections having to do with double awareness of an internal and external object of perception. As I understand it, the worry for sense data theories of perception and memory is, broadly speaking, the following. According to such theories, there is a primary intentional relation that one bears to one's own sense data (call it Int-1), and a further intentional relation that they bear to the world (call it Int-2). They also hold that one can derivately bear an intentional relation, such as perceiving or remembering, to a certain object by being related to a certain sense datum through Int-1 as long as that sense datum is related to the object in question through Int-2. The problem these theories face, then, is that explaining the Int- 2 relation turns out to be just as difficult as it was explaining the nature of perceiving or remembering in the first place.

Meinong's theory of memory invites this kind of objection. When it comes to perception, Meinong has a candidate for Int-1, namely, the relation of experiencing 'what goes on within me'. The problem for Meinong is that positing that relation does not help us to explain what perceiving is. It does not, unless we can explain the relation that, when I perceive something, holds between what I experience (that is, "what goes on within me') and the object of perception. Which seems just as difficult as it was explaining what perceiving is in the first place. When it comes to memory, Meinong has a candidate for Int-1 as well, namely, the relation of 'actually and directly remembering' something. Analogously to the worry above, the fact that we bear the 'directly remembering' relation to the data of our mental life does not help us to explain what remembering is. Meinong still needs to explain the relation that, when I remember something, holds between what I directly remember (that is, the 'data of the mental life') and the object of my remembering. Which seems just as difficult as it was explaining what remembering is in the first place.

\section{Intersecting approaches: Husserl}

Let us now consider Edmund Husserl's views on memory. When Husserl comments on the relation between perception and memory, he emphasizes that the latter is not about the former, thus distancing himself from the reflective theory of memory: 
The memory really implies, therefore, a reproduction of the earlier perception, but the memory is not in the true sense a representation of the perception. The perception is not meant and posited in the memory (Husserl, 1964, p. 82).

Husserl's talk about reproduction here suggests that he endorsed a perceptual theory of memory, which seems to be confirmed by other texts. Thus, Husserl writes:

Present memory is a phenomenon wholly analogous to perception. It has the appearance of the object in common with the corresponding perception (Husserl, 1964, p. 83).

However, Husserl's position on memory is more complicated than this. For he seems to think that, when a subject remembers something, the content of her memory does inherit the content of a previous perception of the subject, but that is only part of the content of her memory. Here is how the two texts above actually continue:

The memory really implies, therefore, a reproduction of the earlier perception, but the memory is not in the true sense a representation of the perception. The perception is not meant and posited in the memory. What is meant and posited in the memory is the object of the perception together with its now, which last, moreover, is posited in relation to the actual now (Husserl, 1964, p. 82).

Present memory is a phenomenon wholly analogous to perception. It has the appearance of the object in common with the corresponding perception. However, in the case of memory the appearance has a modified character, by virtue of which the object stands forth not as present but as having been present (Husserl, 1964, p. 83).

Husserl makes two interesting points in these texts. The first point is that, in addition to the content of a past perception, the content of a memory involves a certain reference to the moment at which the remembered event happened. The second point is that such reference is relative to the subject's temporal location. Let us consider these two points in order.

Husserl's claim that memories and past perceptions share their objects but, in memory, the temporal appearance of those objects is 'modified' suggests that Husserl has a sort of two-factor theory of memory in mind, according to which the content of a certain memory experience is constituted by two elements. The first element is just the event that constitutes the content of a (suitably connected) past perception. The second element is 'its now', that is, the temporal location of the first element. Husserl is quite explicit about this view when he speaks, not specifically about memory, but more generally about intentionality:

The complete apprehension of an object contains two components: the one constitutes the Object according to its extra-temporal determinations; the other creates the temporal position: being-now, having-been, and so on (Husserl, 1964, p. 87).

Now, given the way in which Husserl describes the temporal position of an object when we apprehend it (as being-now, or having-been, for instance), one would expect him to claim that remembered events are presented to us as occupying a certain temporal location relative to our own temporal location. And, indeed, this is how Husserl speaks of the way in which the temporal location of remembered events is presented 
to us in memory. As we have seen, he claims that, in memory, 'the now' of the remembered event is posited 'in relation to the actual now'. In addition, commenting on his example of a remembered lighted theatre, he writes the following (my emphasis):

I remember the lighted theatre of yesterday [...]. Accordingly, the theatre hovers before me in the representation as something actually present. I mean this, but at the same time I apprehend this present as lying back in reference to the actual present of perceptions now extant. [...] What is remembered appears as having been present, that is, immediately and intuitively. And it appears in such a way that a present intuitively appearswhich is at an interval from the present of the actual now (Husserl, 1964, p. 82).

More precisely, Husserl's view seems to be the following. For every subject S, memory experience $\mathrm{M}$ and proposition $\mathrm{p}$ :

\section{Husserl's view}

If $\mathrm{S}$ has a memory experience $\mathrm{M}$ that she would express by saying that she remembers that $\mathrm{p}$, then the content of $\mathrm{M}$ is the proposition:

$<$ Occurring earlier than now, the fact that $\mathrm{p}>$.

This view is, loosely speaking, a perceptual theory in that the content of memory $M$ is meant to inherit one of its elements (namely, the fact that $\mathrm{p}$ ) from a past perception of the remembering subject. ${ }^{10}$ And it is a self-based view in that the other element (namely, the property of occurring earlier than now) crucially involves the time at which the subject remembers. In that sense, the content of a memory experience contains information about the remembering subject.

Once again, whether or not this theory has the resources to deal with AE and AP, it turns out to be quite implausible for independent reasons. Building a temporal reference into the content of memories brings up some significant difficulties for a theory of memory. The main problem for a theory that, like Husserl's, construes such a reference as being relative to the location that the remembering subject occupies is that it makes the content of memories too rich or, in other words, it attributes too much information to memories. The sense in which a theory like Husserl's attributes too much information to memories is that it attributes very demanding truth-conditions to memory experiences. That is, there are memory experiences and possible situations such that, intuitively, those memory experiences are true of those situations and, yet, according to the theory, they turn out not to be true of them.

Consider the following case. In a certain possible situation $\mathrm{W}$, the gorilla is at the zoo at a certain moment in time (call it $\mathrm{t}$ ) and you perceive it to be. Some time later, you travel back in time. In fact, you travel to some period in time before $t$. And, at some point during that period, you have a memory experience $\mathrm{M}$ that you would express by saying that you remember that the gorilla is at the zoo. Now, the question that we should ask ourselves in order to evaluate Husserl's theory is this: Is M true of

10 'Loosely speaking' because our characterization of the perceptual approach in Sect. 4 requires that perceptual theories hold the content of memories to be inherited from the content of corresponding perceptions. However, I will keep speaking of Husserl as a perceptual theorist. The reason is that he thinks of memories as 'reproducing' past perceptions, and he refers to memory as a process 'analogous to' perception. However, not much should really hang on this issue. As we shall see, the criticism I am about to raise against Husserl's position does not concern the perceptual content of memories and, therefore, it does not hinge on whether he is assumed to be a perceptual theorist or not. 
$\mathrm{W}$ or is it false of $\mathrm{W}$ ? Does $\mathrm{M}$ accurately represent $\mathrm{W}$ or not? Intuitively, $\mathrm{M}$ is true of W. After all, your perception of the gorilla is something that does constitute part of your life. It has certainly not become a figment of your imagination just because you travelled back in time. Intuitively, then, $\mathrm{M}$ accurately represents that little segment of your experience. So whatever proposition expresses the content of $\mathrm{M}$, it should give us truth-conditions according to which $\mathrm{M}$ is true of $\mathrm{W}$. However, the content posited by Husserl's theory makes M false of W. The reason is that, in W, the gorilla is not at the zoo before the time that counts as 'now', that is, the time at which you remember. The gorilla is at the zoo at $\mathrm{t}$ and, therefore, after you have M. Thus, we are forced to conclude, quite counter-intuitively, that $\mathrm{M}$ is not representing that portion of your past accurately. The upshot is that Husserl's theory delivers truth-conditions that are too demanding for memories.

\section{Egocentrism in perception and memory}

In the last two sections, we have seen some of the difficulties that Meinong's and Husserl's theories of memory must face. In this section, I shall propose an alternative perceptual, self-based theory. The general strategy I shall follow is to build a reference to the subject into the content of her memories by building it into the content of her corresponding past perceptions. Thus, our first step will require looking at the notion of perceptual content more closely.

Here are two features of perception that any construal of perceptual content should respect. The first one concerns the phenomenology of perceptual states whereas the second one concerns the relation between perception and action.

First of all, perception is perspectival. If you perceive an event to happen then you perceive it from a certain perspective. In fact, it is hard to make sense of the very notion of perceiving something from no point of view or perspective at all. ${ }^{11} \mathrm{In}$ normal circumstances, the perspective from which a perceived event is presented to us is the perspective that we occupy. Thus, I see my computer as being in front of me, I am aware of the smell of coffee coming from behind me, I sense that the air around me is hot, and so on.

Furthermore, perception is immediately salient to action. If you suddenly see a large object flying at your face, then you will duck. Perception directly feeds into action in that you do not need to have any beliefs about your own spatial position relative to the flying object in order to start moving. You do need to have certain background beliefs and desires, such as the belief that there is no reason to distrust your eyes and your desire not to be hit. But it does not seem that you need to have any particular belief about where you are in order to duck.

Immediate salience to action and perspectivity are not surprising features of perception if we assume the following view of perceptual content. Consider a given object $\mathrm{x}$ and property $\mathrm{P}$. (Suppose, for the sake of simplicity, that $\mathrm{P}$ is an intrinsic property of x.) My suggestion is that having a perceptual experience that one would express by saying that one perceives that $\mathrm{x}$ is $\mathrm{P}$ puts one in cognitive contact with the fact that

11 Perhaps we could make sense of that idea by thinking of a possible world where there are no robust correlations between the phenomenological features of our perceptual states and the physical properties of those objects that we perceive. However, I am not sure that we would be inclined to think of the faculties that, in that world, we use when objects in our environment are presented to us as perceptual faculties.

Springer 
$\mathrm{x}$ is $\mathrm{P}$ by putting one in contact with some relational properties of oneself. Typically, the relational property that one is aware of when one is in such a state is one's own spatial location relative to $\mathrm{x}$ being $\mathrm{P}$. Thus, if $\mathrm{I}$ look at the albino gorilla at the zoo under standard conditions, then my perceptual state makes me aware that the gorilla is white by making me aware of my being, say, in front of an albino gorilla. Being in cognitive contact with the fact that an object $\mathrm{x}$ has a given property $\mathrm{P}$ by being in a certain perceptual state may also involve being aware of one's own temperature, shape or size relative to $\mathrm{x}$. Thus, when I am in a perceptual state that I would report by saying that I see a large gorilla, my perceptual state puts me in cognitive contact with the fact that the gorilla is large by putting me in contact with the difference between my own size and the gorilla's. Similarly, when I touch the water in the bathtub and I am in a perceptual state that I would report by saying that I perceive that it is hot, my perceptual state puts me in cognitive contact with the difference between the temperature of the relevant surface of my limb and the temperature of the water.

More generally, for any event $\mathrm{E}$ and subject $\mathrm{S}$, if $\mathrm{S}$ is in a perceptual state that she would report with an utterance of a sentence of the form 'I perceive that E', then there is a relational property $\mathrm{R}$ such that:

(a) $\mathrm{S}$ is one of the two relata of $\mathrm{R}$.

(b) E being the case is the other relatum of $\mathrm{R}$.

(c) The content of S's perceptual state is $<$ Being in relation $\mathrm{R}$ to $\mathrm{E}, \mathrm{S}>$.

The general idea is that the proper object of a perception is always a relational property of oneself. One is aware of facts that occur in one's physical surroundings, independently of one's own existence or acts of perception. But one is aware of them by being aware of some of one's own relations to those facts. In other words, in perception, one is aware of a fact in one's environment as one of the relata of a certain relation that one is aware of taking place (the other relatum of it being oneself). I shall call this view the 'egocentric' view of perceptual content. ${ }^{12}$

A certain constraint must be imposed on the relational properties of oneself that, according to this view, one is aware of in perception. These cannot be intentional properties, such as thinking of, representing, or being aware of something. They cannot be, for two different reasons. The first reason is that intentional relations can be instantiated even if the represented object does not exist. Thus, if we allowed the egocentric view to claim that, in perception, one is aware of, let us say, representing a gorilla, then the possibility of massive error about the outside world would be consistent with my perceptual faculties working correctly. (I could perceive correctly in the sense of correctly being aware of representing a gorilla.) And this raises an important sceptical worry. ${ }^{13}$ The second reason is that if we allow the egocentric view to claim that, in perception, one is aware of such intentional relations as representing a gorilla, then the view will be vulnerable to the very same kind of criticism that we raised against Meinong's theory of memory: Explaining the relations that, according to the egocentric view, enter into the content of perceptual states will turn out to be just as difficult as explaining the relation that the view is meant to illuminate by positing them, namely, the relation of perceiving. ${ }^{14}$

12 The point that information about oneself may be contained in the content of one's own perceptual states is not new. It is characteristic of J. J. Gibson's 'ecological optics', for instance, in his (1979).

13 I appreciate that an anonymous referee has brought this worry to my attention.

14 I am grateful to an anonymous referee for raising this issue. 
Fortunately, the kind of relational properties of oneself that, according to the egocentric view, one is aware of in perception is a different kind of properties. As the examples above suggest, they are non-intentional properties such as having a certain size, location or temperature relative to that of another object. Clearly, the skeptical worry does not arise here because they are not properties that could be instantiated if the other relatum did not exist. I cannot, for instance, occupy a certain location relative to that of another object if that other object does not exist. Similarly, since the relational properties that, according to the egocentric view, are involved in the content of perceptual states are not intentional, the worry that we brought up against the sense data theory of memory does not apply to the egocentric view. The relational properties in question are physical relations and, therefore, there should be nothing mysterious about analyzing perceiving as awareness of those relations being instantiated.

The egocentric view of perceptual content fits the perspectival character of perception. If, in perception, one is aware of an event by being aware of a relational property of oneself that involves that event as the other relatum of it, then it is not surprising that one cannot perceive an event but from a certain perspective. The reason is that one's perceptual awareness of a certain event from a certain perspective just is the awareness of one's own spatial position, shape, size and so on relative to an event. Quite simply, that is all there is to perceiving an event 'from a certain point of view'. The egocentric view also squares with the tight connection between perception and action. If the egocentric view is correct then, when I perceive a given object, I am always aware of myself as well as some of the relations that hold between me and that object. Thus, in the flying object example, I am aware of the object as flying at $m e$. That is, I am aware of my position relative to the object when I perceive it. My own spatial position relative to the object is directly presented to me in perception. No wonder that I do not need to have any beliefs about it to start moving. ${ }^{15}$

It is important to appreciate that this explanatory power comes at a cost. ${ }^{16}$ The egocentric view has some prima facie puzzling consequences. The view individuates the intentional objects of perception very finely. Thus, if the view is correct, then no two people can ever perceive, strictly speaking, the same event. If you and I were at the zoo looking at the gorilla, for instance, and the gorilla tried to jump the fence, then you and I did not perceive the same thing when we watched in awe. This is admittedly odd. However, there is a sense in which the intuition that there is something common to what you and I perceived is preserved in the egocentric view. For one of the two relata in the intentional object of my perception is the same as one of the two relata in the intentional object of yours. There is, then, a clear sense in which we share at least part of what we perceive.

In addition, the egocentric view of perception can help us build a theory of memory that accounts for AP and AE. Recall the two conditions for memory that characterize

\footnotetext{
15 An anonymous referee for this journal has pointed out that many other theories of perceptual content could do the first explanatory task just as well. It is certain true that a theory of perceptual content could illuminate the perspectivity of perception by appealing, for instance, to relational properties of, not the subject who perceives, but her location in space. Thus, one might claim that if I occupy position $\mathrm{x}$ in space at the time I seem to perceive an object that is flying at me, then the content of my perceptual experience is $<$ there being an object flying towards it, $\mathrm{x}>$. But if position $\mathrm{x}$ is not indexically described (as 'here' or 'this place', for instance), then this view will have some difficulties accounting for the fact that perception is immediately salient to action. And if $\mathrm{x}$ is indexically described, then it should be possible to reformulate such a view in terms of relational properties of the subject.

16 I am grateful to an anonymous referee for bringing this to my attention.

黑 Springer
} 
the perceptual framework. For any subject S, memory M and event E, if S has $\mathrm{M}$ and the content of $\mathrm{M}$ is that $\mathrm{E}$, then:

(a) Previous perception condition

$\mathrm{S}$ has previously perceived that E.

(b) Dependency condition

The fact that $\mathrm{S}$ perceived that $\mathrm{E}$ is responsible for her having $\mathrm{M}$ now.

Consider the following constraint on perceptual content imposed by the egocentric view of perception. For any subject $\mathrm{S}$ and event $\mathrm{E}$, the following holds if the egocentric view of perception is correct:

(c) Egocentric constraint on perceptual content

If $\mathrm{S}$ perceives that $\mathrm{E}$, then $\mathrm{E}$ is the instantiation of a relational property of $\mathrm{S}$.

The egocentric constraint on perceptual content yields a perceptual theory of memory that is self-based as well. This theory is simply the conjunction of the egocentric view of perception and the conditions for memory specified by the perceptual framework: We remember those events that we previously perceived, provided that the previous perceptions are appropriately connected to the present memories. And those events that we have previously perceived are the instantiation of relational properties of ourselves that involve independent events in our physical surroundings as the other relata. I shall call this theory the 'egocentric view' of memory.

We can now use the morals we drew from our discussion of perceptual and selfbased theories to account for AP and AE quite straightforwardly. The egocentric view falls into the perceptual framework. This means that we can offer the above-discussed strategies regarding vividness, overlap of context and difficulty of access as a promising approach to AP within the egocentric view. The point is not that the egocentric view commits us to pursuing that kind of explanation of AP. (There may very well be other ways to explain AP that are compatible with that view.) Still, there seems to be no reason why construing the object of our perceptions as relational properties of ourselves should affect the prospects of those strategies regarding vividness, overlap of context and difficulty of access. Thus, there seems to be at least one kind of explanation of AP that is available to the egocentric view, just as it is generally available to any perceptual theory of memory. Furthermore, AE is no longer a mystery within the egocentric view. Suppose that the egocentric view is correct. Then, if one is in the kind of intentional state that one would typically express by saying that one remembers a certain event, one is being aware of a relational property of oneself that involved that event. This means that memory guarantees a certain form of self-awareness, namely, awareness of being in a certain relation to the remembered event. Which explains our tendency to believe that we existed at the time that the remembered event happened. Why do I believe that I existed at the time that the albino gorilla that I remember was living at the zoo? Because what I remember is, strictly speaking, my being in front of an albino gorilla at the zoo. I am, so to speak, as much part of the content of my memory as the gorilla is. For I was as much part of the content of the relevant past perception as the gorilla was. It is not surprising then, that my memory elicits the belief that I existed at the time the gorilla was at the zoo.

Finally, the egocentric view also accounts for an additional fact about memory that we have not been focusing on, namely, the perspectivity of memory. We remember 
an event from a certain perspective or point of view, just like we perceive events from a point of view. Now, if the egocentric view is correct, then that point of view is not arbitrary. It is the very same point of view from which the event was previously perceived. This allows us to make sense of a very familiar sort of experience. It is possible that you remember a certain object or place that you have not seen in a long time as having certain dimensions and, when you encounter it again, you are surprised to find that those dimensions do not correspond to the object or place that you are now perceiving. For instance, one remembers the room where one used to sleep as a child as having a high ceiling but, when one revisits the old house, one finds that the room in question has a rather low ceiling. This is exactly what we should expect if the egocentric view is correct. For the content of one's current perception of the room is partly determined by the current relation between one's height and the height of the ceiling. But the content of one's memory of it was partly fixed by the past relation that, for a period of time during one's childhood, held between one's height and that of the ceiling. Now, that relation has changed over time as one grew up. So the property of oneself that contributed to determining the content of one's current perception of the room differs from the property that once helped to fix the content of one's memory of it. This explains why the content of one's own current perception does not match the content of one's memory any more.

The upshot is that adopting the egocentric view of perception allows us to obtain the right sort of theory for memory. It can explain AP by appealing to the resources available to perceptual theories and it can explain AE by appealing, ultimately, to the egocentric view of perception. Furthermore, it can account for the perspectivity of memory. My conclusion is that the right account of episodic memory for perceivable events should conjoin the egocentric theory of perception with the previous perception and dependency conditions on mnemonic content that characterize perceptual theories of memory.

\section{References}

Anisfeld, M., \& Knapp, M. (1968). Association, synonymity, and directionality in false recognition. Journal of Experimental Psychology, 77, 171-179.

Baddeley, A. D. (1982). Domains of recollection. Psychological Review, 89, 708-729.

Brown, N. R., Rips, L. J., \& Shevell, S. K. (1985). The subjective dates of natural events in very-longterm memory. Cognitive Psychology, 17, 139-177.

Gibson, J. J. (1979). The ecological approach to visual perception. Boston: Houghton Mifflin.

Glenberg, A. M., Bradley, M. M., Kraus, T. A., \& Renzaglia, G. J. (1983). Studies of the long term recency effect: Support for the contextually guided retrieval hypothesis. Journal of Experimental Psychology: Learning, Memory, and Cognition, 9, 231-255.

Glenberg, A. M., Bradley, M. M., Stevenson, J. A., Kraus, T. A., Tkachuk, M. J., Gretz, A. L., Fish, J. H., \& Turpin, B. M. (1980). A two-process account of long-term serial position effects. Journal of Experimental Psychology: Human Learning and Memory, and Cognition, 6, 355-369.

Godden, D. R., \& Baddeley, A. D. (1975). Context-dependent memory in two natural environments: On land and underwater. British Journal of Psychology, 66, 325-331.

Hinrichs, J. V. (1970). A two-process memory-strength theory for judgment of recency. Journal of Experimental Psychology: General, 108, 356-388.

Hume, D. (1978). A treatise of human nature. L. A. Selby-Bigge (Ed.). Oxford: Oxford University Press.

Husserl, E. (1964). The phenomenology of internal time-consciousness. M. Heidegger (Ed.). Bloomington: Indiana University Press.

Jacoby, L. L., \& Dallas, M. (1981). On the relationship between autobiographical memory and perceptual learning. Journal of Experimental Psychology: General, 110, 306-340. 
Martin, M. G. F. (2001). Out of the past: Episodic recall as retained acquaintance. In C. Hoerl, \& T. McCormack (Eds.), Time and memory: Issues in philosophy and psychology. Oxford: Oxford University Press.

Meinong, A. (1973). Toward and epistemological assessment of memory. In R. M. Chisholm, \& R. J. Swartz (Eds.), Empirical knowledge: Readings from contemporary sources. Englewood Cliffs: Prentice Hall.

Morton (1968). Repeated items and decay in memory. Psychonomic Science, 10, 219-220.

Reid, T. (1994). Inquiry and essays. R. E. Beanblossom, \& K. Lehrer (Eds.). Indianapolis: Hackett.

Russell, B. (1921) The analysis of mind. London: Allen and Unwin.

Tulving, E. (1972). Episodic and semantic memory. In W. Donaldson, \& E. Tulving (Eds.), Organization of memory. New York: Academic Press. 